\title{
Neuroplasticity-related correlates of environmental enrichment combined with physical activity differ between the sexes
}

\author{
N. Kokras ${ }^{a, b, 1}$, I. Sotiropoulos ${ }^{c, d, a, 1}$, D. Besinis ${ }^{a}$, \\ E.L. Tzouveka ${ }^{a}$, O.F.X. Almeida ${ }^{e}$, N. Sousa ${ }^{c, d}$, C. Dalla ${ }^{a, *}$
}

${ }^{a}$ Department of Pharmacology, Medical School, National and Kapodistrian University of Athens, Mikras Asias 75, Athens 11527, Greece

${ }^{\mathrm{b}}$ First Department of Psychiatry, Eginition Hospital, National and Kapodistrian University of Athens, Athens, Greece

'Life and Health Sciences Research Institute (ICVS), University of Minho, Braga, Portugal

'ICVS/3B's, PT Government Associate Laboratory, Braga, Portugal

e Max Planck Institute of Psychiatry, Munich, Germany

Received 6 March 2018; received in revised form 1 November 2018; accepted 9 November 2018

Available online $x x x$

\section{KEYWORDS}

Sex differences;

Enriched environment;

Hippocampus;

Receptors;

Serotonin;

Dopamine

\begin{abstract}
Environmental enrichment (EE), comprising positive physical (exercise) and cognitive stimuli, influences neuronal structure and usually improves brain function. The promise of EE as a preventative strategy against neuropsychiatric disease is especially high during early postnatal development when the brain is still amenable to reorganization. Despite the fact that male and female brains differ in terms of connectivity and function that may reflect early life experiences, knowledge of the neural substrates and mechanisms by which such changes arise remains limited. This study compared the impact of EE combined with physical activity on neuroplasticity and its functional consequences in adult male and female rats; EE was provided during the first 3 months of life and our analysis focused on the hippocampus, an area implicated in cognitive behavior as well as the neuroendocrine response to stress. Both male and female rats reared in EE displayed better object recognition memory than their control counterparts. Interestingly, sex differences were revealed in the effects of EE on time spent exploring the objects during this test. Independently of sex, EE increased hippocampal turnover rates of dopamine and serotonin and reduced expression of $5-\mathrm{HT}_{1 \mathrm{~A}}$ receptors; in addition, $\mathrm{EE}$ upregulated expression of synaptophysin, a presynaptic protein, in the hippocampus. As compared
\end{abstract}

* Corresponding author.

E-mail address: cdalla@med.uoa.gr (C. Dalla).

${ }^{1}$ Both the authors contributed equally to this work. 
to their respective controls, EE-exposed males exhibited parallel increases in phosphorylated Tau and the GluN2B receptor, whereas females responded to EE with reduced hippocampal levels of glutamate and GluN2B. Together, these observations provide further evidence on the differential effects of EE on markers of hippocampal neuroplasticity in males and females. (C) 2018 Elsevier B.V. and ECNP. All rights reserved.

\section{Introduction}

A multiplicity of environmental factors, acting on highlyplastic developing neural substrates, contribute to the structure and function of the adult brain, including its ability to respond to further challenges and opportunities (Bredy et al., 2004; Callaghan and Tottenham, 2016; Murgatroyd et al., 2009; Wu et al., 2014). Numerous studies have focused on the mechanisms underlying the negative impact of early adverse environments on mood and cognition (Sousa, 2016; Vyas et al., 2016). At the same time, several studies suggest that enriched environments (EE, e.g. exposure to novel and/or complex stimuli, and physical exercise) enhance behavioral performance (Simpson and Kelly, 2011a) or even revert age-related neuropathology and cognitive impairments deficits (Nithianantharajah and Hannan, 2006; Sifonios et al., 2009). The neuroplastic phenomena involved in EE-induced improvements in function include increased cortical and hippocampal volume/thickness, and enhanced neurogenesis, synaptogenesis and dendritic branching (Bindu et al., 2007; Fischer, 2016). Although the beneficial effects of EE are widely acknowledged, analysis of the literature reveals considerable variability in the size of effects observed; this variability is likely attributable to the type and duration of EE, and sex and age of the subjects at the time of EE. For example, we previously reported that EE may engage different neurochemical and molecular mechanisms in brains of young/adolescent vs. adult rats (Bessinis et al., 2013) and that external stressors impact differently in terms of neuroplastic and behavioral responses in the two sexes (Dalla et al., 2010; Sotiropoulos et al., 2015). Nevertheless, very few studies have examined how EE during early life influences brain development in females (Connors et al., 2015; Girbovan and Plamondon, 2013a; Kentner et al., 2018; Simpson and Kelly, 2011a). The present study represents a more detailed systematic analysis of how EE during the first 90 days of postnatal life alters a number of neuroplastic mechanisms implicated in the manifestation of neuropsychiatric-like symptoms in adult rats of both sexes. The clinical relevance of this work becomes amply apparent when one considers evidence from a large-scale survey that there are major sex differences in vulnerability to, and incidence and severity of, the majority of neuropsychiatric conditions (Kokras and Dalla, 2017; Wittchen et al., 2011).

\section{Experimental procedures}

\subsection{Animals and treatments}

All experiments were conducted in accordance with the guidelines for the care and handling of laboratory animals in EU Directive 2010/63. The timeline of the exper- iment is depicted in Fig. 1. Specifically, pregnant Wistar rats were housed in individual cages until they gave birth when, together with their litters they were either housed in enriched or standard conditions, as described below. Litters were culled to 10 each (both sexes) on postnatal day 3 (P3) and weaned at postnatal day 26 (P26), as previously described (Bessinis et al., 2012;2013). Rats were then housed according to sex and per-weaning conditions, under either standard conditions (CON males, $n=7$; CON females, $n=7$ ) or in environmentally-enriched (EE) set-ups (EE males $n=7$, EE females, $n=7$ ). Generally, all animals experienced standard animal housing conditions (lights on from 8 a.m. to 8 p.m.; room temperature $22^{\circ} \mathrm{C}$; relative humidity of $55 \%$, ad libitum access to food and water), but the EE-exposed groups were maintained in larger cages, measuring W $80 \mathrm{~cm} \times$ D $49 \mathrm{~cm} \times \mathrm{H} 38 \mathrm{~cm}$ (Criceti16 cages, IMAC, Vincenza, Italy) that were equipped with two running wheels, an "upper floor", two tunnels, 2 feeding bowls, 3 water bottles, and two plastic play items (house, measuring $165 \times 100 \times 110 \mathrm{~mm}$ and a bridge, measuring $205 \times 65 \times 100 \mathrm{~mm}$ ); the positions of all objects were changed every second day, and the space was reorganized, as previously described (Bessinis et al., 2013). It should be noted that the existence of the running wheels contributes to the EE by combining physical activity as well. Control (non-enriched) animals were housed in standard laboratory cages measuring $W 60 \mathrm{~cm} \times$ D $40 \mathrm{~cm} \times \mathrm{H} 20 \mathrm{~cm}$. Vaginal smears were examined on a daily basis between P83 and P90 to determine estrous cycle phase (Kokras et al., 2015). The distribution of cycle phases on P90, when animals were killed, was: CON females in proestrous/estrous $(n=4)$, diestrous I or II $(n=3)$, and EE females in proestrous/estrous $(n=3)$, diestrous I and II $(n=4)$. Male and female rats were killed $48 \mathrm{~h}$ after the behavioral tests (Fig. 1) by rapid decapitation when their trunk blood was collected, and brains were excised and snap-frozen and stored at $-80^{\circ} \mathrm{C}$ until further analysis (see below). The blood serum was assayed for corticosterone using a radioimmunoassay kit (MP Biomedicals, Costa Mesa, CA), as previously described (Kafetzopoulos et al., 2018; Kokras et al., 2012). The interand intra-assay coefficients of variation were both $8 \%$.

\subsection{Behavioral tests}

The Open Field (OF) test was used to measure locomotor and exploratory behavior and as an index of anxiety (time spent in the center). The OF was a Plexiglass chamber (W40 x D40 x H40; Med Assoc., USA) with automatic movement detection. All animals were exposed to the OF on P86, after being acclimated to the test room for $1 \mathrm{~h}$ prior to testing. Individual rats were introduced into the center of the OF and allowed to freely move within it for 5 min after which 


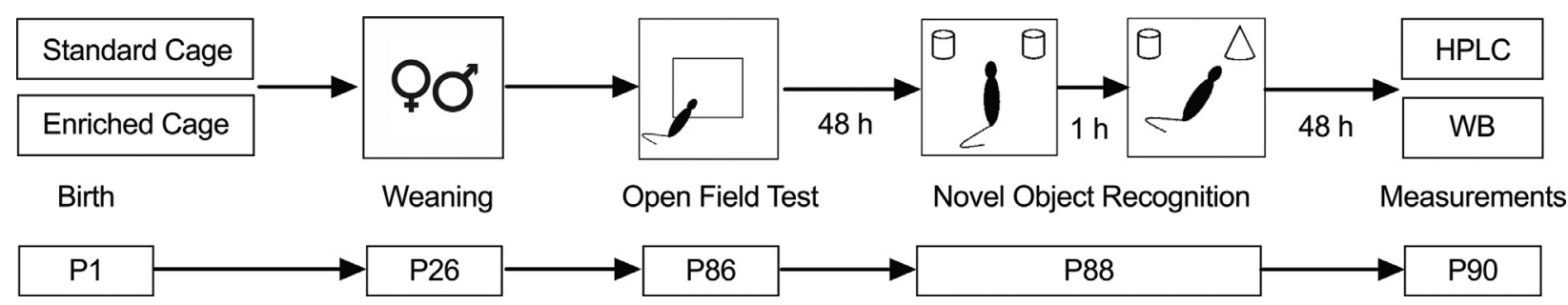

Fig. 1 Timeline of the experimental procedures. P1, P26, P86, P88, P90 refers to postnatal days. HPLC = High Performance Liquid Chromatography. WB $=$ Western Blot.

they were returned to their home cages. The OF arena was cleaned thoroughly (70\% and 10\% ethyl alcohol) before the next rat was tested. Behavior during each trial was video recorded and locomotor activity, rearing behavior and number of entries and time spent in the center of the open field was scored using Activity Monitor software (version 5, Med Associates, Fairfax, VT, USA), as described previously (Kokras et al., 2012; 2018).

A Novel Object Recognition (NOR) test served to assess one aspect of cognition (non-spatial working memory) on P88. Animals were familiarized with the test room for $1 \mathrm{~h}$ before being introduced into the NOR apparatus which consisted of the OF (described above) in which 2 objects were placed. Rats were placed at the center of the apparatus during 2 trials of 10 min each (separated by an interval of $60 \mathrm{~min}$, with cleaning of the test arena - as before - between consecutive trials). This version of the NOR, which depends on functional integrity of the hippocampus (Clark et al., 2000), was previously used to detect sex differences in the effect of EE (Sutcliffe et al., 2007b). During Trial 1 (T1), the objects in the arena were identical and the time spent exploring these was recorded. During Trial 2 (T2), one of the objects was replaced by a new object (object $B$ ) that differed from the first (object $A$ ) in terms of color, shape and texture, and the time spent exploring each of the objects was recorded. Metal objects (rounded and white with colored stripes) were used before introduction to the novel object that was made of glass (black, bottle-shaped). A preference index was computed from time spent exploring novel object $(N) /$ total time spent exploring both objects $(\mathrm{N}+\mathrm{O})$ in T2. Data acquisition and analysis was done using Kinoscope software (Gemmel et al., 2017; Kokras et al., 2017).

\subsection{Neurochemical assays}

Dopamine (DA) and serotonin (5-HT) were measured in hippocampal extracts. Briefly, one-half of the brain of each animal was homogenized, deproteinized (in $500 \mu \mathrm{L}$ of $0.1 \mathrm{~N}$ perchloric acid solution containing $7.9 \mathrm{mM}$ $\mathrm{Na}_{2} \mathrm{~S}_{2} \mathrm{O}_{5}$ and $1.3 \mathrm{mM} \mathrm{Na}{ }_{2}$ EDTA), and centrifuged $(15,000 \mathrm{~g}$, $\left.45 \mathrm{~min}, 4^{\circ} \mathrm{C}\right)$, after which the recovered supernatants were stored at $-80^{\circ} \mathrm{C}$ until analysis. High-PerformanceLiquid-Chromatography (HPLC) detection of dopamine and serotonin was carried out using a GBC LC1150 (GBC Inc, Braeside, Australia) apparatus, outfitted with an Aquasil C18 column $(150 \mathrm{~mm} \times 2.1 \mathrm{~mm} ; 5 \mu \mathrm{m}$ particle size; Thermo Fisher Scientific, Massachusetts, USA) and coupled to a electrochemical detector set at $+800 \mathrm{mV}$ (BAS LC4C, Bio- analytical Systems, USA). HPLC was performed following a previously-described protocol (Gemmel et al., 2016; Morgado et al., 2015), with minor modifications. Reverse-phase ion pair chromatography (mobile phase: $50 \mathrm{mM}$ phosphate buffer at $\mathrm{pH} 3.0$, containing $300 \mathrm{mg} / \mathrm{L}$ sodium octylsulfate, $20 \mathrm{mg} / \mathrm{L} \mathrm{Na}{ }_{2}$ EDTA, and acetonitrile added at a concentration of 6-9\%) was used to assay dopamine (DA) and its metabolites 3,4 dihydroxyphenylacetate (DOPAC) and homovanillic acid (HVA), and serotonin (5-HT) and its metabolite 5hydroxyindoleatic (5-HIAA). Reference standards were prepared in $0.1 \mathrm{~N}$ perchloric acid solution, containing 7.9 $\mathrm{mM} \mathrm{Na}_{2} \mathrm{~S}_{2} \mathrm{O}_{5}$ and $1.3 \mathrm{mM} \mathrm{Na} \mathrm{m}_{2}$ EDTA. Transmitter concentrations were quantified by comparison of areas under the curve (AUC) with those obtained with external reference external standards, using Clarity software (Data-Apex, Czech Republic); the sensitivity of the assay was $1 \mathrm{pg} / 20 \mathrm{ul}$ of injection volume. An index of serotonergic and dopaminergic activity was obtained from estimations of DA (HVA/DA and DOPAC/DA ratios) and 5-HT (5-HIAA/5-HT ratio); these activities reflect transmitter release and/or metabolic activity (Kyratsas et al., 2013; Mikail et al., 2012).

Hippocampal tissue levels of glutamate were measured by HPLC, using a GBC LC1150 (GBC Inc, Braeside, Australia) pump coupled to a BAS LC4C electrochemical detector, after pre-column derivatization. Minor modifications of a previously-described method were used (Kokras et al., 2009; Melo et al., 2015). Briefly, a glass-carbon working electrode (set at $+800 \mathrm{mV}$ ), an $\mathrm{Ag} / \mathrm{AgCl}_{2}$ reference electrode, and a Hypersil Gold aQ $(150 \mathrm{~mm} \times 2.1 \mathrm{~mm}$, $5 \mu \mathrm{m}$, from Thermo Fisher Scientific) were used. The mobile phase consisted of a $5 \%$ acetonitrile in $100 \mathrm{mM}$ monosodiumphosphate buffer ( $\mathrm{pH} 5.5$ ), containing $0.5 \mathrm{mM} \mathrm{Na}{ }_{2}$ EDTA. Samples were initially diluted $1: 100$ with $\mathrm{ddH}_{2} \mathrm{O}$, then further diluted $1: 1$ with $0.1 \mathrm{M}$ borax buffer $(\mathrm{pH} 10.4)$ to which o-phthalaldehyde was added; this mixture was left to stand at room temperature for 10 min prior to injection. Comparison of areas under the curve (samples vs. reference external standards) using Clarity software, allowed quantification of glutamate levels.

\subsection{Immunoblotting}

One-half of each hippocampus was homogenized in lysis buffer, as described previously (Kokras et al., 2011; Sotiropoulos et al., 2011). After centrifugation (14,000 g, $15 \mathrm{~min}, 4^{\circ} \mathrm{C}$ ), protein contents were estimated by Bradford assay. After reconstitution in Laemmli buffer, lysates were boiled at $95^{\circ} \mathrm{C}$ for $10 \mathrm{~min}$ and electrophoresed (BIO-RAD Mini-Protean Tetra Cell Electrophoresis Electrode 
Tank) on $10 \%$ acrylamide gels and transferred onto nitrocellulose membranes (BIORAD Turbo). Membranes were blocked in Tris-buffered saline, containing 5\% nonfat dried milk powder and $0.2 \%$ Tween-20 before incubation with the following antibodies: Tau5 (1:2000; Abcam, Cambridge, UK), PHF1 (p-Ser396/404-Tau; 1:200; kindly provided Dr. Peter Davies (Albert Einstein College of Medicine, New York, NY), GluNR2B (1:1000; Abcam), GluA2 (1:500; Abcam), PSD95 (1:5000; NeuroMab, Davis, CA, USA), Synaptophysin (1:5000; Synaptic Systems, Goettingen, Germany), Synapsin I (1:5000; Synaptic Systems), and 5-HT $\mathrm{HA}_{1 \mathrm{~A}}$ receptor (1:2500), as well as GAPDH (1:1000; Santa Cruz Biotechnology, Heidelberg, Germany). The Western blots were scanned and quantified using TINA 3.0 bioimaging software (Raytest, Straubenhardt, Germany) after ascertaining linearity. All values obtained for proteins of interest were normalized to levels of GAPDH and expressed as percentages of control male animals; however, pTau levels were normalized to total Tau levels.

\subsection{Statistical analysis}

Results were analyzed with SPSS v.24 (IBM Corp, NY, US) after controlling that all data met pre-conditions of ANOVA. For all experiments, a two-way ANOVA was performed with sex (male; female) and environment (SE, standard environment; EE, enriched environment) as independent variables. A similar ANCOVA, but with the addition of the cycle as a covariate, showed no significant effect of the stage of the cycle. Significant Sex $X$ Environment interactions were further explored with post-hoc pairwise comparisons with Bonferroni type I error correction. Statistical significance was set at $p<0.05$. Results are reported as means \pm standard error of the mean (SEM).

\section{Results}

\subsection{Physiological parameters influenced by early-life environmental enrichment $(E E)$}

As expected, male rats had significantly greater body weights than females $\left[F_{1,24}=4498.265, p<0.001\right]$, but $\mathrm{EE}$ did not influence body weight gains in either sex [CON Males $=332 \pm 36$ gr; EE males: $346 \pm 19$ gr; CON females $=230 \pm 13$ gr; EE female $=224 \pm 9$ gr, data not shown in figures].

A two-way ANOVA revealed a Sex x EE interaction on corticosterone levels $\left[\mathrm{F}_{1,24}=3.93, p=0.05\right]$ and post hoc tests showed that females reared under EE conditions (EE) had higher circulating levels of corticosterone than males in $\mathrm{EE}$ $(p=0.045)$ (Fig. 2(A)).

\subsection{Early-life environmental enrichment (EE) improves object recognition memory in both sexes but enhances object's exploration only in males}

Results of behavior in an open field (OF) arena are shown in Fig. 2(B) and (C). Two-way ANOVA analysis failed to detect sex-related differences in locomotion, as measured by locomotor activity and rearing behavior which, in the unhabituated open field test, are indicative of emotionality and exploratory motivation (Antoniou et al., 1998). However, a main effect of Sex $\left[F_{1,24}=4.196, p=0.05\right]$ was identified by monitoring the number of entries in the center and a similar trend was observed for the time spent into the central area of the arena $\left[F_{1,24}=4.020, p=0.056\right]$, with females making overall more such entries than males and spending marginally more time in the center (Fig. 2(D) and (E)).

Using the novel object recognition (NOR) test to assess the influence of $\mathrm{EE}$ on one aspect of cognitive behavior (Fig. 2(F) and (G)), we uncovered a significant interaction between Sex and $E E$ in the percentage of time spent exploring objects during the training session $\left[F_{1,24}=9.467\right.$, $p=0.005]$. Post hoc analysis revealed differences in exploratory behavior for both objects between males raised under control vs. EE conditions $(p=0.005)$ and between EEreared males and females $(p=0.007)$ (Fig. $2(F))$. A significant Sex and EE interaction was also found with respect to the total object-exploration time in the test phase of the NOR paradigm $\left[F_{1,24}=7.556, p=0.011\right]$, with post hoc tests revealing greater exploration times by CON females vs. CON males $(p=0.005)$ and vs. EE females $(p=0.001)(F i g .2(F))$. Thus, EE differentially shaped the adaptation strategies of male and female rats during the training and test sessions of the NOR. Further, analysis of the object preference data revealed a main effect of $E E\left[\mathrm{~F}_{1,24}=9.109, p=0.014\right]$, with both sexes displaying an increased preference index during the test phase (Fig. 2(G)).

\subsection{Sex-specific influence of EE on neurochemical markers of hippocampal plasticity}

Given that neuroplastic changes in the hippocampus are thought to underpin the cognitive effects of $E E$ (Nithianantharajah and Hannan, 2006; Simpson and Kelly, 2011b), we next examined how EE during early life impacts key neurochemical molecules in the adult hippocampus. Analysis revealed a main effect of $E E$ on dopamine (DA) levels $\left[F_{1,24}=4.885, p=0.036\right](F i g .3(A))$ and a significant interaction between Sex and $E E$ on the levels of a major DA metabolite, DOPAC $\left[F_{1,20}=21.90, p=0.0001\right]$. Followup post hoc analysis showed that DOPAC levels were higher in the hippocampus of EE-exposed males vs. CON males $(p<0.001)$ and EE-treated females $(p<0.001)$, as depicted in Fig. 3(B). A significant main effect of EE was also observed on levels of the other DA metabolite HVA $\left[F_{1,24}=15.37\right.$, $p=0.0006$; Fig. $3(C)$ ]. Since monoamine turnover rates are considered to be more reliable indices of monoaminergic than absolute monoamine (and metabolite) levels because they integrate information regarding transmitter synthesis, release, reuptake and metabolism (Novais et al., 2013), we also computed DOPAC/DA and HVA/DA ratios. The latter showed that EE significantly increased DOPAC/DA ratios in both sexes) $\left[F_{1,24}=21.59, p=0.0001\right.$; Fig. $\left.3(D)\right]$ but had no effect on HVA/DA ratios (Fig. 3(E)).

Examination of serotonergic activity in the hippocampus did not reveal sex- or environmental-related differences in tissue serotonin (5-HT) levels (Fig. 4(A)). However, a main effect of EE was observed on 5-HIAA levels 

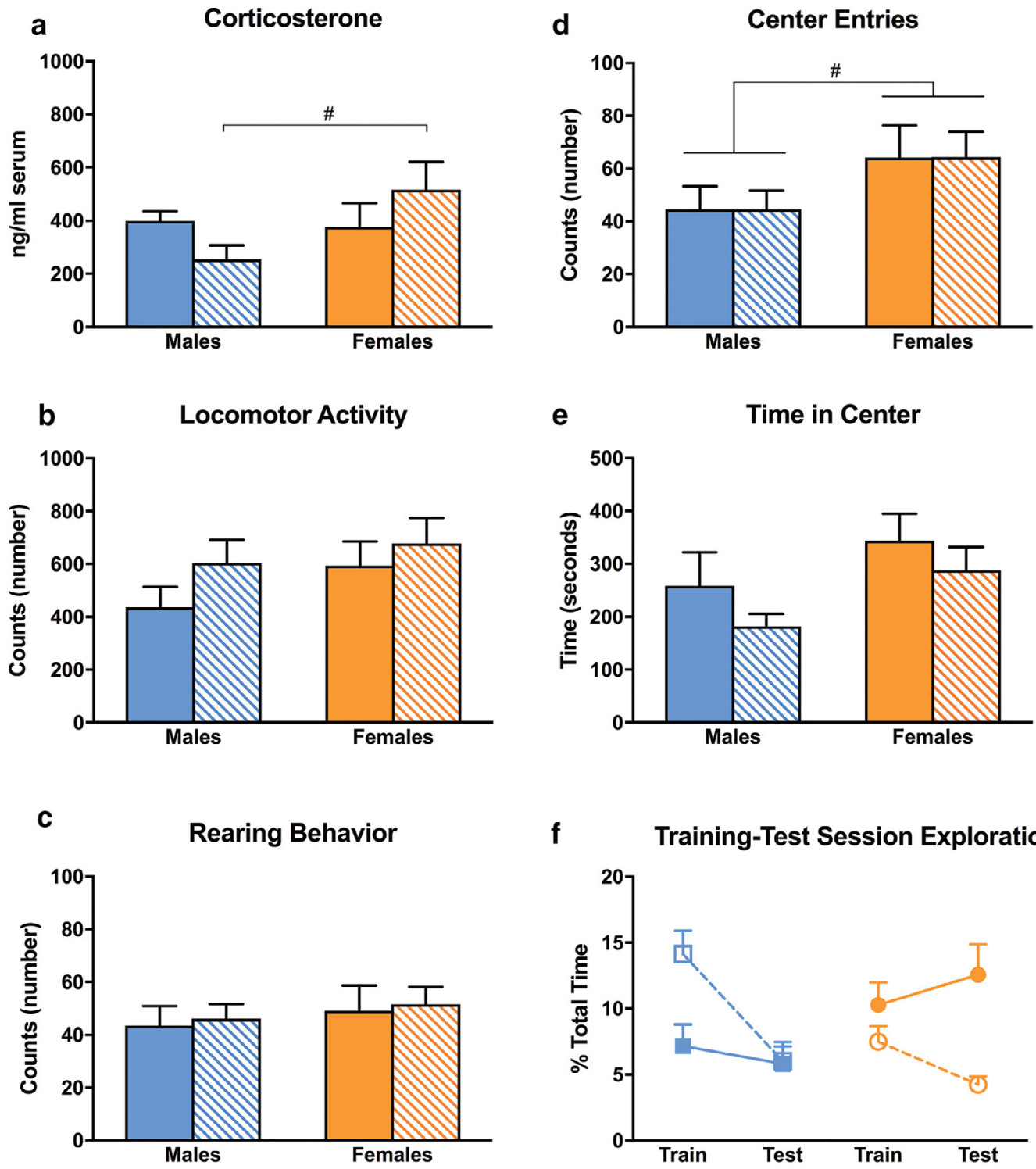

$\mathbf{f}$
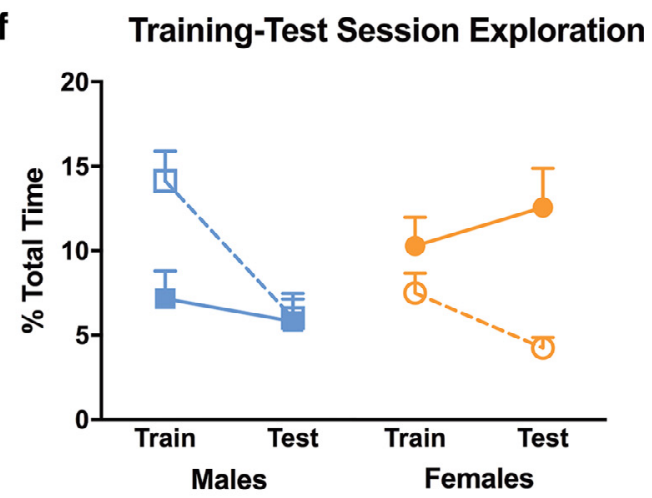

g
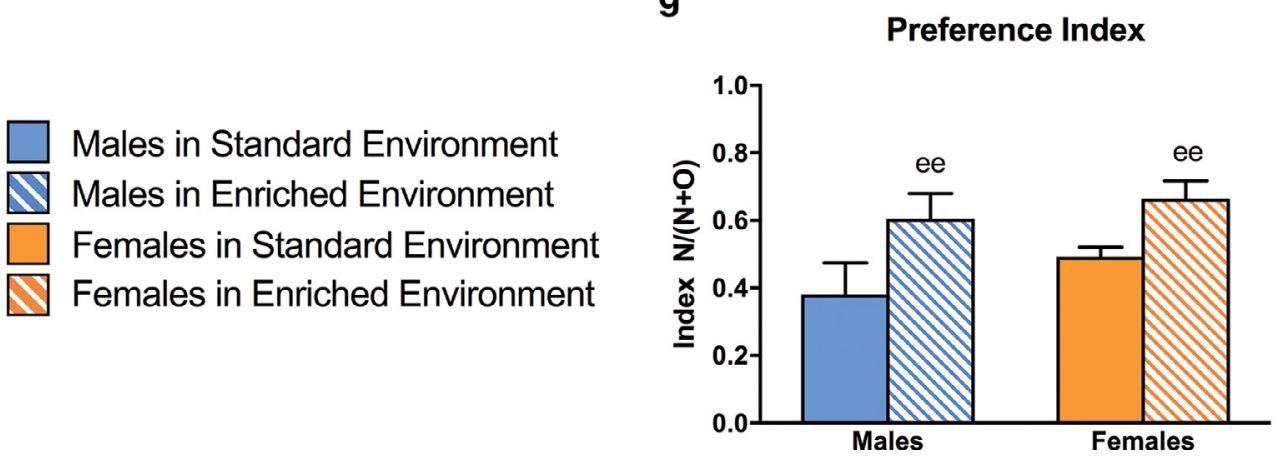

Fig. 2 Corticosterone levels (a) and behavior during the Open Field Test (b,c,d,e), the Novel Object Recognition test (f,g) in male and female animals, following exposure to environmental enrichment (EE, lined bars and doted line at panel $f$ ) or standard environment (solid bars and solid line at panel f). A hash sign (\#) denotes a sex difference, as indicated by the two-way ANOVA. A main effect of EE in the absence of a significant interaction is indicated with "ee". $N=7$ per group. Values are presented as means \pm standard error of mean (SEM). 
a

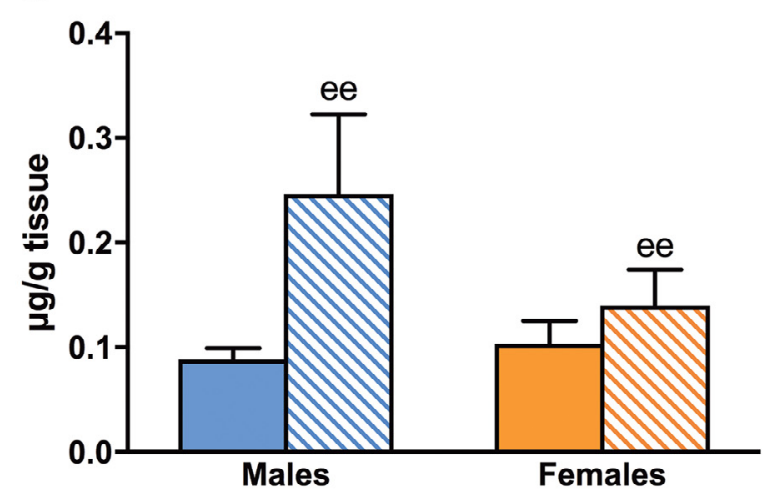

b

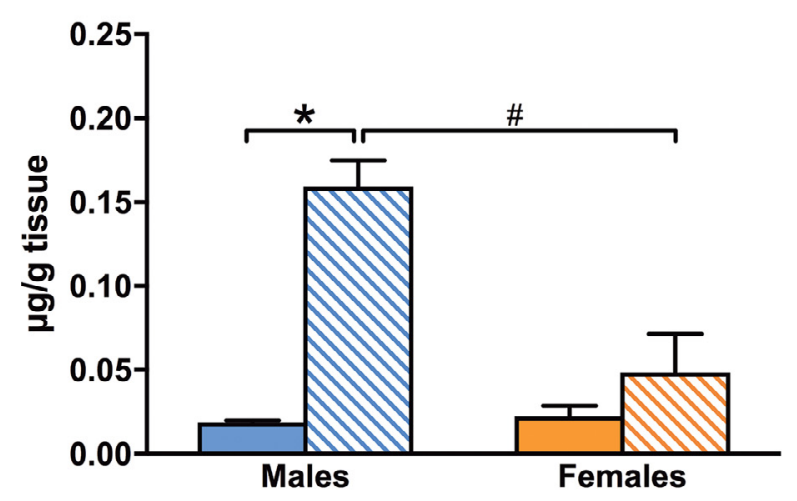

Males in Standard Environment Males in Enriched Environment Females in Standard Environment Females in Enriched Environment c

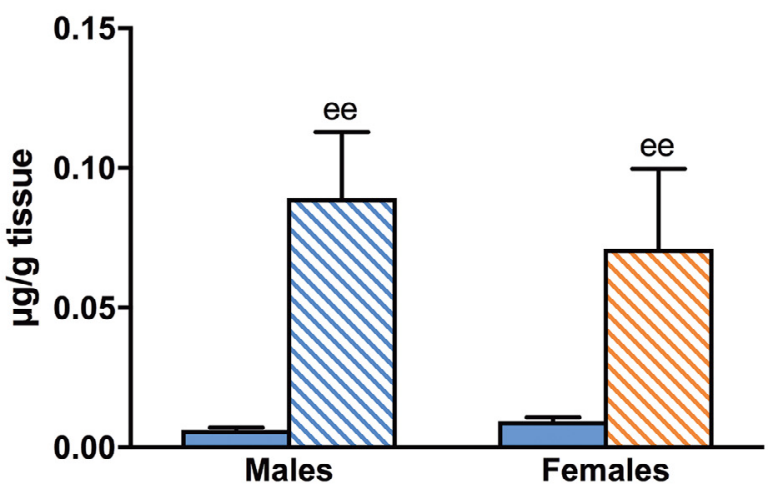

d

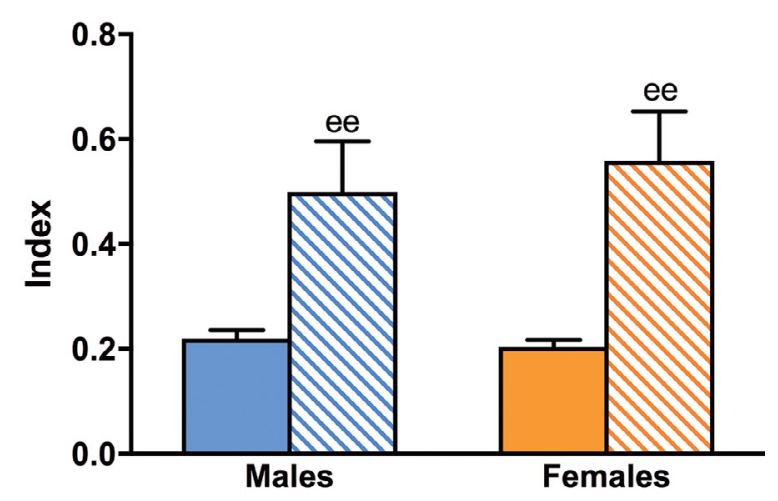

e HVA/DA

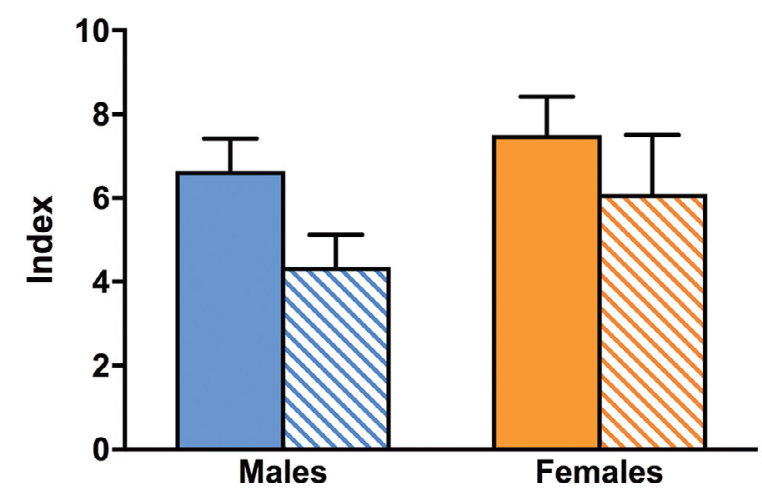

Fig. 3 Effect of exposure to environmental enrichment (EE, lined bars) or standard environment (SE, solid bars) in the dopaminergic neurotransmission of male and female rats. Tissue levels of (a) dopamine (DA), (b) DOPAC (c) HVA, and turnover rates of (d) DOPAC/DA and (e) HVA/DA. An asterisk $\left({ }^{*}\right)$ denotes an effect of environmental enrichment and a hash sign (\#) a sex difference, as indicated by the two-way ANOVA. $N=7-9$ per group. A main effect of EE in the absence of a significant interaction is indicated with "ee". Values are presented as means \pm standard error of mean (SEM).

$\left[\mathrm{F}_{1,23}=6.518, p=0.018\right]$, due to increased levels of this 5-HT metabolite in both sexes exposed to EE. Furthermore, females displayed higher tissue levels of 5-HIAA than males $\left[F_{1,23}=12.134, p=0.002\right.$; Fig. 4(B)]. With respect to $5-\mathrm{HT}$ turnover, measured as the ratio of $5-\mathrm{HIAA} / 5-\mathrm{HT}$, two-way ANOVA revealed a significant main effect of $E E$ $\left[F_{1,22}=5.402, p=0.03\right]$ and $\operatorname{Sex}\left[F_{1,22}=24.905, p<0.001\right]$, with females exhibiting higher turnover rates than males (Fig. 4(C)). Investigation of the effects of EE on serotonin receptor $1 \mathrm{~A}\left(5-\mathrm{HT}_{1 \mathrm{~A}}\right)$ levels by immunoblotting, showed that this receptor is significantly influenced by EE in the hippocampus of both sexes $\left[F_{1,24}=5.034, p=0.034\right]$. Moreover, $5-\mathrm{HT}_{1 \mathrm{~A}}$ levels were also subject to regulation by Sex, with 
a

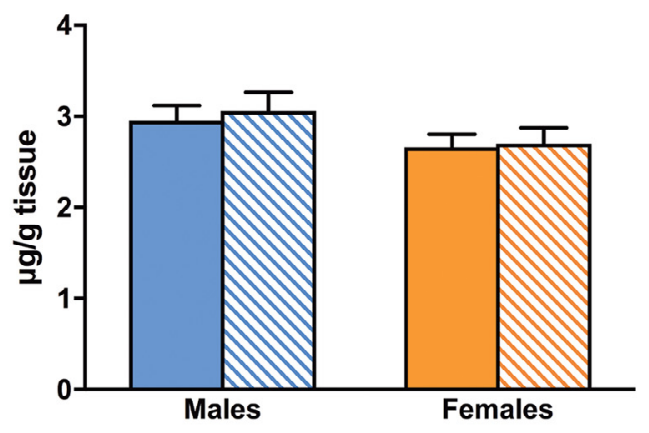

b

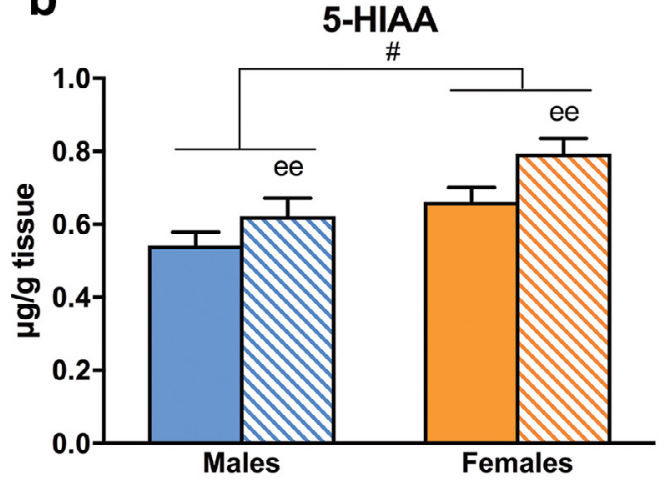

C 5-HT Turnover Rate

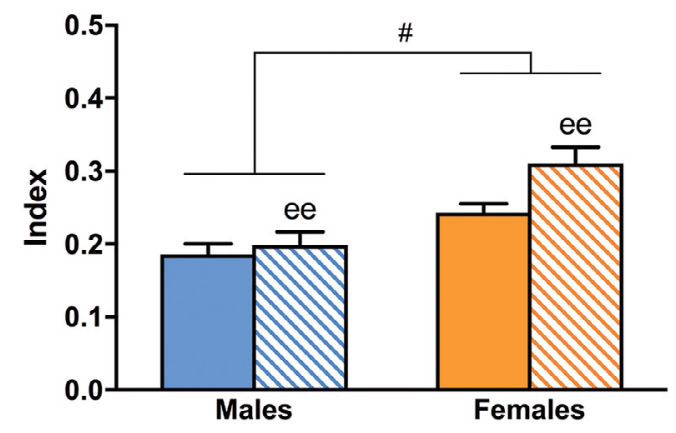

d

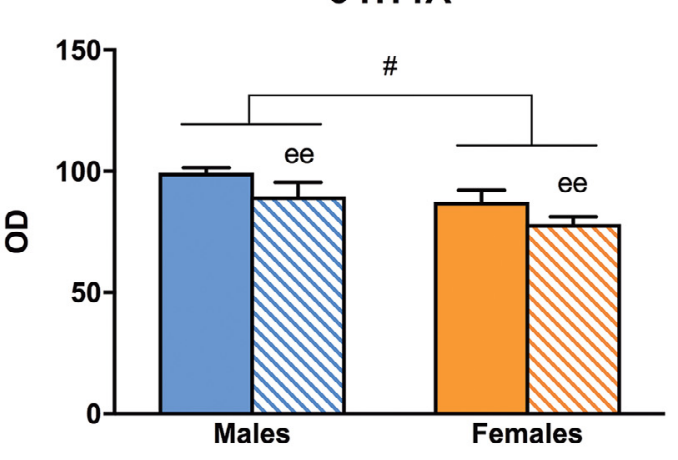

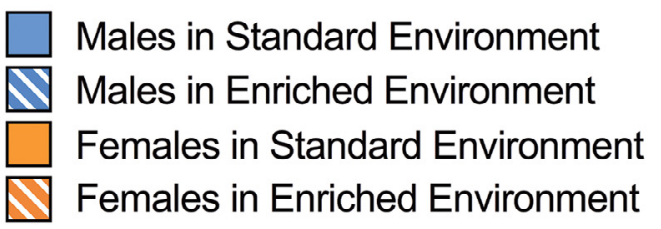

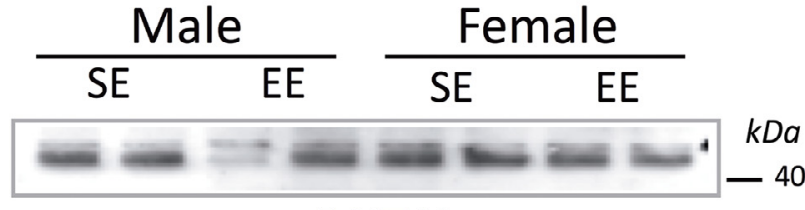

5-HT1A

Fig. 4 Effect of exposure to environmental enrichment (EE, lined bars) or standard environment (SE, solid bars) in the serotoninergic neurotransmission of male and female rats. Tissue levels of (a) serotonin (5-HT), (b) 5-HIAA, and (c) serotonin turnover rate (5-HIAA/5-HT), and (d) immunoblots of 5-HT1A receptor. An asterisk $\left({ }^{*}\right)$ denotes an effect of environmental enrichment and a hash sign (\#) a sex difference, as indicated by the two-way ANOVA. $N=7$ per group. A main effect of EE in the absence of a significant interaction is indicated with "ee". Values are presented as means \pm standard error of mean (SEM). OD = Optical Density units, after normalization against male control animals. Protein results were normalized to GAPDH (see Fig. 6). Representative images of Western blots are also presented for male and female control animals raised in a standard environment (SE), as well as animals raised in environmental enrichment $(\mathrm{EE})$.

female hippocampi expressing lower levels than those found in male tissues $\left[F_{1,24}=7.753, p=0.01\right.$, Fig. 4(D)].

We next assessed how EE affects hippocampal levels of glutamate. Our data revealed a significant Sex X EE interaction on tissue glutamate levels $\left[F_{1,23}=17.00, p<0.001\right]$. Specifically, glutamate levels were significantly lower in EEexposed females compared to CON females $(p<0.001)$ and although levels of this transmitter were higher in the hippocampus of CON females vs. CON males $(p=0.036)$, they were lower in tissue extracts from EE-reared females than EE-reared males $(p=0.002)$ (Fig. $5(\mathrm{~A}))$. Immunoblot analysis revealed an interaction between Sex and $E E$ with respect to hippocampal levels of GluN2B subunit-containing NMDARs $\left[\mathrm{F}_{1,24}=16.430, p<0.001\right]$. Post hoc analysis showed that EE-reared males had increased levels of GluN2B as com- pared to their male counterparts $(p=0.002)$ and that EEreared females express decreased GluN2B levels as compared to CON females $(p=0.038)$ (Fig. 5(B)); further, it emerged that EE-exposed males express higher levels of this receptor subunit than EE-exposed EE females $(p<0.001)$. Notably, GluA2 subunit-containing NMDAR levels were similar among all groups (Fig. 5(C)).

Immunoblot analysis was subsequently performed on hippocampal tissue extracts obtained from CON and EEexposed male and female rats. This analysis showed that $E E$ increased the expression of synaptophysin levels in both sexes $\left[F_{1,24}=7.087, p=0.014\right.$; Fig. $\left.6(A)\right]$ while Sex was revealed to be also an important variable, with females expressing higher levels of synaptophysin than males $\left[F_{1,24}=14.351, p=0.001\right]$ (Fig. $6(A)$ ). In addition, a 

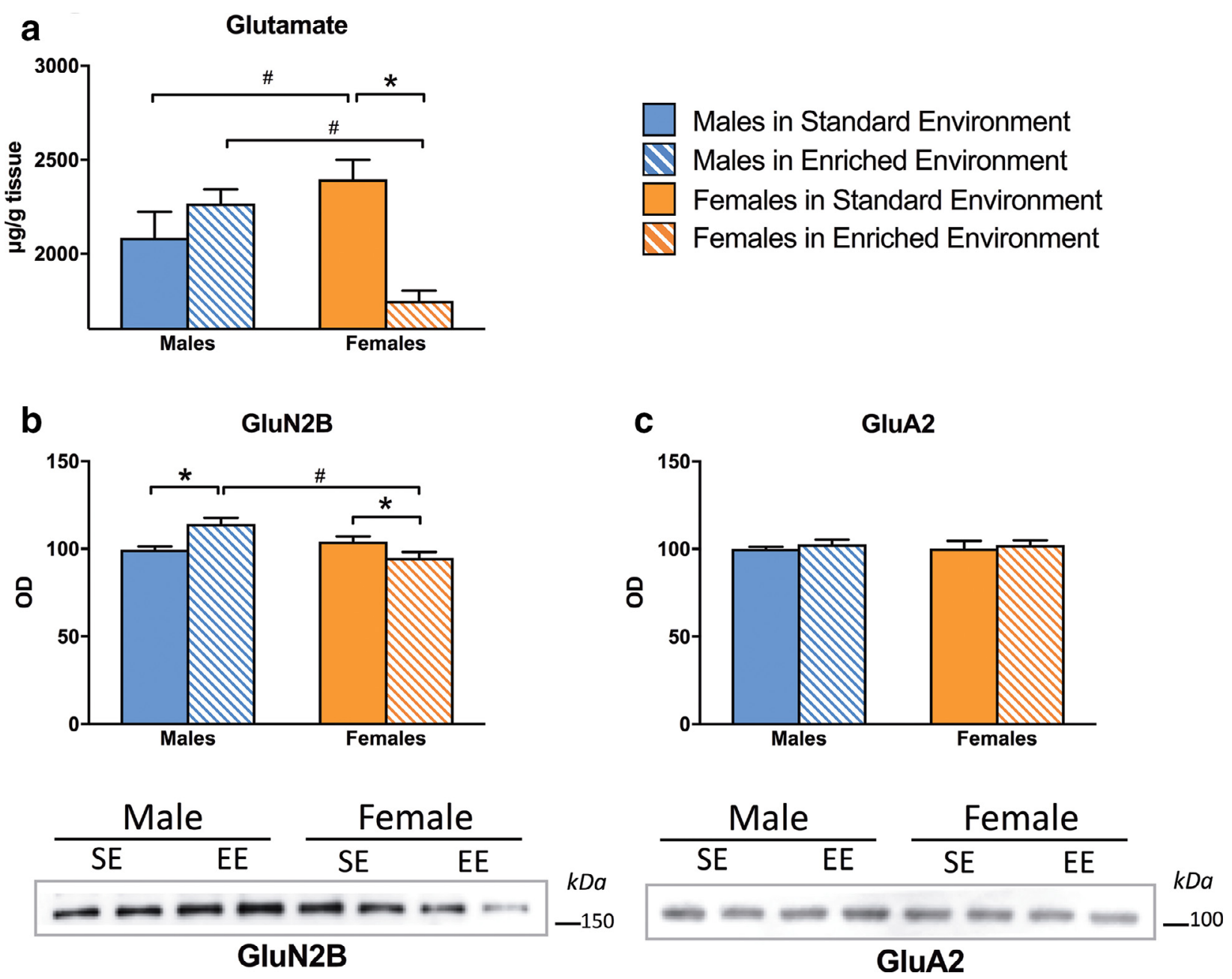

Fig. 5 Effect of exposure to environmental enrichment (EE, lined bars) or standard environment (SE, solid bars) in the glutamatergic neurotransmission of male and female rats. Tissue levels of (a) glutamate, and western blotting of (b) GluN2B and (c) GluA2 receptors. An asterisk $\left({ }^{*}\right)$ denotes an effect of environmental enrichment and a hash sign (\#) a sex difference, as indicated by the two-way ANOVA. $N=7$ per group. A main effect of EE in the absence of a significant interaction is indicated with "ee". Values are presented as means \pm standard error of mean (SEM). OD = Optical Density units, after normalization for male control animals. Protein results were normalized to GAPDH (see Figure 6). Representative images of Western blots are also presented for male and female control animals raised in a standard environment (SE), as well as animals raised in environmental enrichment (EE).

non-significant trend for $E E$ to influence synapsin expression in a sex-dependent manner was observed (Fig. 6(B)).

A significant Sex $X E E$ interaction was found with respect to hippocampal levels of the post-synaptic density protein PSD95 $\left[F_{1,24}=9.028, p=0.006\right]$; specifically, EE-reared females displayed higher levels of PSD95 than CON females $(p=0.001)$ and EE-exposed males $(p=0.05)($ Fig. $6(C))$.

Since a role in regulating synaptic function has recently been ascribed to the cytoskeletal protein Tau (Frandemiche et al., 2014), we also compared the levels of total and phosphorylated Tau in hippocampal extracts from CON and EE-reared male and female rats. While total Tau levels did not differ between groups (Fig. 7(A), a twoway ANOVA revealed a significant interaction between Sex and EE in the regulation of phospho-Ser396/404-Tau (p396/404 Tau) $\left[F_{1,24}=11.935, p=0.002\right]$; briefly, EEexposed males exhibited higher levels of p396/404 Tau than CON males $(p=0.002)$ and EE-reared females $(p<0.001)$ (Fig. 7(B)).
In summary, the behavioral and neurochemical findings described above strongly suggest that the cognitiveenhancing effects of EE are underpinned by largely different mechanisms in the hippocampus of male and female rats.

\section{Discussion}

This study was designed to examine whether and how environmental enrichment (EE) from birth to adulthood impacts on cognitive performance and neuroplasticity in male and female rats. While there is an abundant literature that shows that short-term EE improves cognition and can even ameliorate the effects of cognitive-impairing neuropathologies [for review see (Blazquez et al., 2014; Pang and Hannan, 2013; Simpson and Kelly, 2011a)], there are fewer reports in which long-term EE (approximately 3 months in this study) was applied (Simpson and Kelly, 2011a). Secondly, studies involving EE have been done mostly in male rodents 

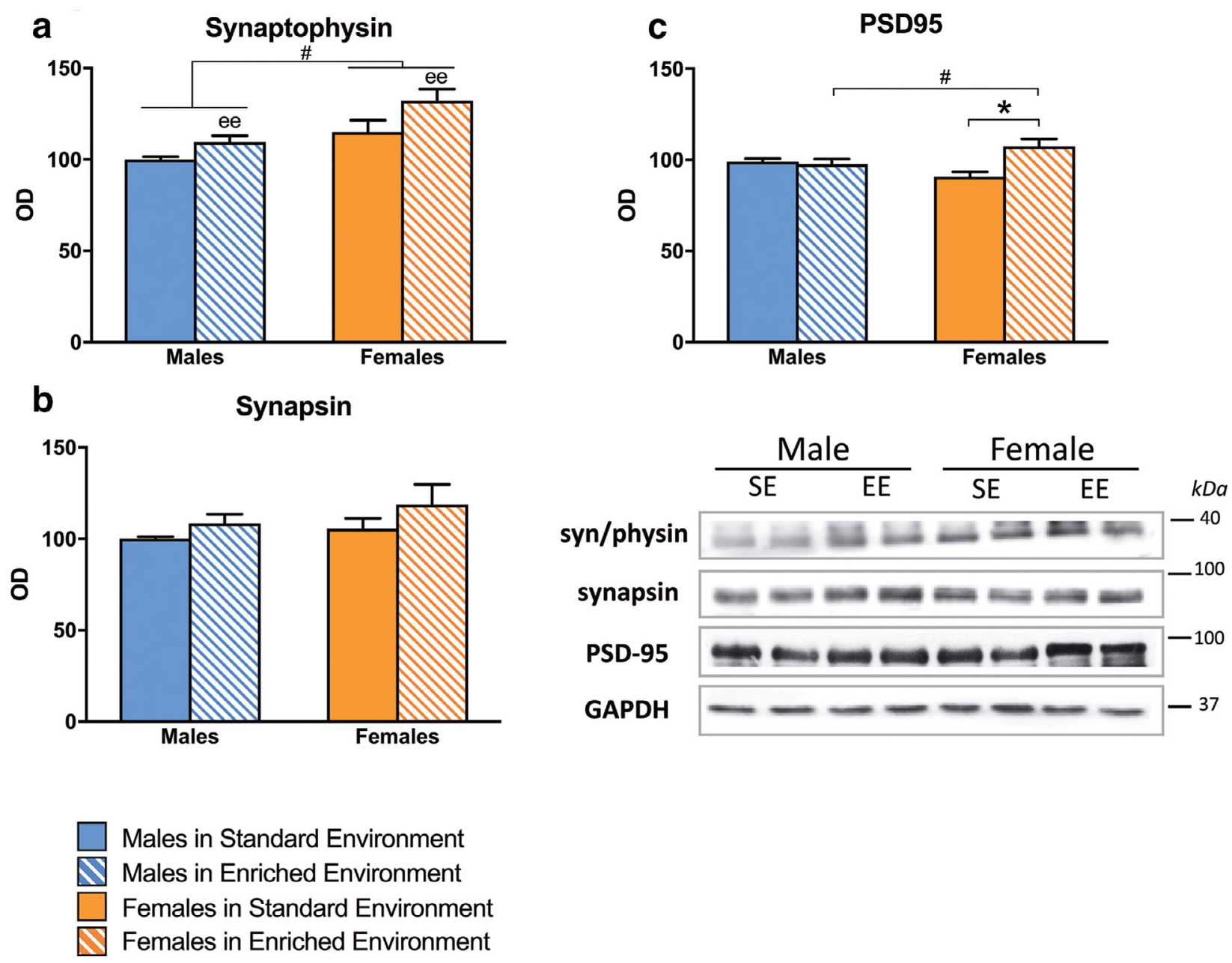

Fig. 6 Effect of exposure to environmental enrichment (EE, lined bars) or standard environment (SE, solid bars) in the expression of (a) synaptophysin, (b) synapsin, (c) PSD95 in the hippocampus of male and female rats. An asterisk (*) denotes an effect of environmental enrichment and a hash sign (\#) a sex difference, as indicated by the two-way ANOVA. A main effect of EE in the absence of a significant interaction is indicated with "ee". $N=7$ per group. Values are presented as means \pm standard error of mean $(\mathrm{SEM}) . \mathrm{OD}=$ Optical Density units, after normalization for male control animals. Protein levels were normalized to GAPDH levels. Representative images of Western blots are also presented for male and female control animals raised in a standard environment $(\mathrm{SE})$, as well as animals raised in environmental enrichment (EE).

[but see (Blazquez et al., 2014; Girbovan and Plamondon, 2013b; Hendershott et al., 2016; Kentner et al., 2018; Pena et al., 2009)]. Thus, the present study adds further knowledge to understanding how long-term EE differentially influences behavior of males and females. Thirdly, we sought to identify potential neurochemical players that may contribute to behavioral alterations resulting from chronic EE exposure; for this, we focused on the hippocampus since neuroplasticity in this brain region is strongly implicated in adaptive and cognitive behaviors (Cameron and Schoenfeld, 2018; Shors, 2004; Sousa and Almeida, 2002).

Exposure to EE did not alter spontaneous locomotion of male and female rats in the OF test; this observation is largely consistent with previous reports on the effect of EE on locomotor activity (Del Arco et al., 2007; Hattori et al., 2007; Läck et al., 2010). On the other hand, as compared to male rats, female rats exhibited overall enhanced entries into the center of the OF entries, indicating their lower levels of anxiety, as previously reported and reviewed in detail elsewhere (Kokras and Dalla, 2014; Kokras et al., 2012;2018). Importantly, the present study demonstrated that rearing under EE conditions from early life, does not alter basal anxiety levels in either sex. Overall, effects of EE on locomotion and emotionality seem to depend on several factors, such as duration of enrichment, strain of animals, etc. (Connors et al., 2015; Girbovan and Plamondon, 2013b; Li et al., 2016).

In line with previous studies (Beck and Luine, 2002; Bowman et al., 2003; Frick and Gresack, 2003; Luine, 2002), we observed sex differences, albeit subtle, in the NOR test by scoring behavior during both the training and test sessions (Sutcliffe et al., 2007a). In fact, our data suggest that both EE-exposed males and females show memory improvements, suggested by enhanced preference for the new object in the second (test) trial of the NOR test. However, males and females display differential strategies in performing the NOR test. Briefly, EE males spent more time exploring the two identical objects during the training 
a
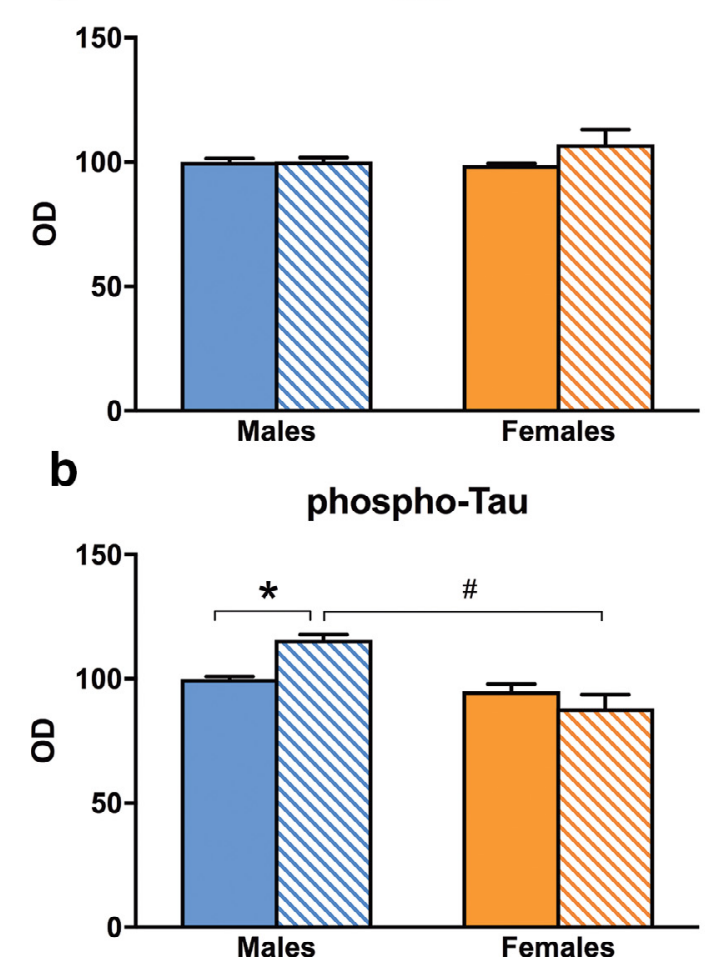

Males in Standard Environment Males in Enriched Environment Females in Standard Environment Females in Enriched Environment

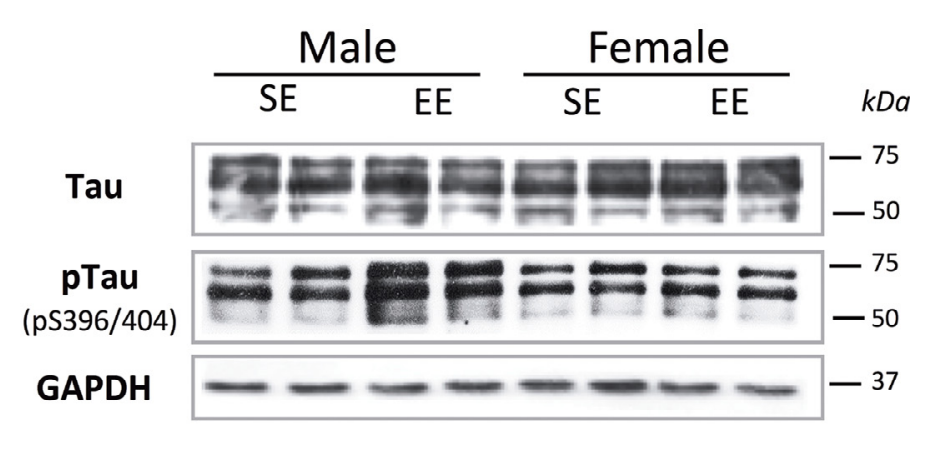

Fig. 7 Effect of exposure to environmental enrichment (EE, lined bars) or standard environment (SE, solid bars) in the expression of (a) total tau and (b) phosphorylated tau in the hippocampus of male and female rats. An asterisk $\left({ }^{*}\right)$ denotes an effect of environmental enrichment and a hash sign (\#) a sex difference, as indicated by the two-way ANOVA. $N=7$ per group. Values are presented as means \pm standard error of mean (SEM). OD = Optical Density units, after normalization for male control animals. Tau levels were normalized to GAPDH levels and pTau levels were normalized to total Tau levels. Representative images of Western blots are also presented for male and female control animals raised in a standard environment (SE), as well as animals raised in environmental enrichment $(\mathrm{EE})$.

trial than controls, whereas this was not apparent in the test trial (equal exploration time between EE and control males). On the other hand, EE females spent approximately the same time, as controls, exploring the two identical objects in the training trial, but required less exploration time as compared to controls, during the test trial, when they were presented with two non-identical objects.

It is worth noting that the cognitive-enhancing effects of EE found in this study could be potentially related to altered maternal care due to the effects of EE on the mother and/or the beneficial effects of EE on the pups (Connors et al., 2015; Li et al., 2016). Indeed, experiences acquired between birth and weaning are critical for the regulation of neurodevelopment and the acquisition of behavioral traits in newborn rodents and primates (Fleming et al., 1999). Previous studies suggest that sensory stimulation from the mother during this period of high developmental plasticity exerts an important influence on the developing subject (Liu et al., 2000; Ronca et al., 1993), in terms of physical growth and maturation, including on those brain structures involved in cognitive functions (Fleming et al., 1999).

Complex interactions between maternal care and the activity of the HPA axis (Bagot et al., 2012), with ultimate effects on learning and memory (Moore et al., 2013), have been reported previously. EE has been reported to either have no effect on circulating corticosterone levels (Bakos et al., 2009; Kentner et al., 2018; Pena et al., 2009), to increase them (Arndt et al., 2009), or to reduce them (Harati et al., 2013; Van de Weerd et al., 1997), and to prevent their rise under stressful conditions (Welberg et al., 2006), (for reviews see (Girbovan and Plamondon, 2013a;2013b; McQuaid et al., 2012; Simpson and Kelly, 2011a)). Here, we observed higher levels of corticosterone secretion in EE females compared to EE males, suggesting EE-Sex interactions. However, this conclusion is limited by the fact that we did not observe herein sex differences in basal corticosterone levels between male and female rats (Kokras et al., 2012). In this respect, strain, housing conditions and gonadal hormone levels may play a critical role (Bangasser and Valentino, 2014; Dalla et al., 2005; Kokras et al., 2018).

Notably, the external environment plays a key role in determining brain structure, chemistry and function, and therefore mental health. The brain is highly malleable during early postnatal development, but it tends to become more resistant to change with age. As mentioned before, EE ameliorates the effects of adverse events by promoting neuroplastic mechanisms (Kentner, 2015). Extending those earlier studies, the present work shows that chronic (90 days) exposure to EE enhances DAergic transmission in the hippocampus of both sexes. This result is interesting because hippocampal DA is crucial for optimal cognitive 
function (Dalla et al., 2008). Since DA is involved in the encoding of novel contextual information, as well as in selective attention and spatial learning (Kempadoo et al., 2016; Moreno-Castilla et al., 2017), our observations could explain how EE improves performance in the NOR by both sexes. The EE paradigm used here also enhanced 5-HTergic activity in the hippocampus (with a contemporaneous decrease in the expression of $5-\mathrm{HT}_{1 \mathrm{~A}}$ receptor protein levels) of male and female rats. Notably, increased 5-HTergic transmission was previously suggested to mediate EE-induced plasticity (Baroncelli et al., 2010; Brenes et al., 2008). Since stress-induced impairments of behavior are accompanied by altered 5-HTergic activity (Dalla et al., 2005; Pitychoutis et al., 2012), all of these observations together suggest a role for $5-\mathrm{HT}$ in the beneficial effects of EE.

It has been reported that EE-induced neuroplasticity is characterized by increases in spine number that are not accompanied by major alterations in spine size distribution (Nithianantharajah and Hannan, 2006). In line with this, we found that EE increases hippocampal levels of synaptophysin, a presynaptic protein required for vesicle fusion and neurotransmitter release (Greengard et al., 1993; Rehm et al., 1986), previously found to be increased in the female rodent brain, irrespective of exercise or cognitive stimulation levels (Lambert et al., 2005). As reported previously (Sifonios et al., 2009), we also found that EE enhances expression levels of the post-synaptic protein PSD-95 which plays a central role in plasticity of glutamatergic synapses, including the formation of spines (Coley and Gao, 2018). Strikingly, however, the EE-induced increase in PSD-95 levels was only found in the hippocampus of females, an observation that could be related to sex differences in this index of neuroplasticity (Carvalho-Netto et al., 2011). This is line with the reported sex-dependent increase of BDNF levels in females exposed to EE in adulthood, possibly reflecting sex differences in basal neuroplasticity (Bakos et al., 2009). Since neuroplastic and -chemical responses may strongly depend on specific types of stimulation, it should be noted that our protocol included both enrichment and exercise. Exercise, within the EE paradigm, is known to improve working memory and increase indices of hippocampal neuroplasticity, whereas EE alone modifies anxiety (Lambert et al., 2005; Rogers et al., 2016). Such effects of EE seem to be differentiated along the dorsal-ventral axis of the hippocampus in male rodents (Gualtieri et al., 2017; Tanti et al., 2012; Zhang et al., 2018; Zheng et al., 2017), with implication of the dorsal hippocampus in the cognitive benefits of EE and exercise, and the ventral hippocampus in the perception and sensation of pain (Zheng et al., 2017). Given that the hippocampus displays sex differences in neuroplasticity, such as in neurogenesis (Dalla and Shors, 2009) and the density of dendritic branching and synapses (Andrade et al., 2000; Dalla et al., 2009; Shors et al., 2001), further studies are necessary to understand the molecular basis for the sex-specific effects of EE on hippocampal neuroplasticity along the dorsal-ventral hippocampus axis.

Recent work from our own and other labs have shown that one physiological function of the microtubule-associated cytoskeletal protein Tau (Bakota et al., 2017) is to regulate and maintain the dynamic structure and function of synapses (Kimura et al., 2014; Kobayashi et al., 2017). Rear- ing under EE conditions did not influence total hippocampal levels of Tau in either males or females. However, EE increased the amount of hyperphosphorylated Tau (at Ser $396 / 404$ ) in the male hippocampus, a finding of particular interest because i) the somatodendritic distribution of Tau depends upon phosphorylation of the protein (Frandemiche et al., 2014; Pooler et al., 2012) and ii) Tau is required for the induction of synaptogenesis and the regulation of spine morphology by brain-derived growth factor (BDNF) (Chen et al., 2012), a neurotrophin known to be upregulated by a variety of EE protocols (Nithianantharajah and Hannan, 2006). Information derived from research on Tau, in the context of neuroplasticity and neurodegeneration (Ittner et al., 2010; Lopes et al., 2016), indicates that during neuronal hyperexcitability, hyperphosphorylated Tau stabilizes GluN2B glutamate receptors at the synapses by targeting Fyn kinase to the postsynaptic density (PSD) complex (Kornau et al., 1995; Lee et al., 1998; Trepanier et al., 2012). In the present study, the EE-induced increase in Tau phyophorylation in males was accompanied by increased GluN2B levels. In stark contrast, EE in females reduced glutamate levels, failed to induce Tau hyperphosphorylation and downregulated GluN2B protein expression, suggesting a possible mechanism that underpins the sex-specific responses to EE. These interesting findings show that males and females in response to EE have the same behavioral phenotype, although with differential behavioral strategies, but some elements of the endophenotype are either the same (i.e. monoaminergic changes) or different (i.e. glutamatergic changes and phospho-Tau). Differences in the endophenotype could correspond to other behavioral effects that were not investigated here. For example, spatial, emotional or other types of learning/conditioning (Dalla and Shors, 2009) as well as anhedonia (Mileva and Bielajew, 2015) could have been influenced by EE in a sex-dependent way with effects on the outcomes measured in this work. Nevertheless, the influence of sex-hormonal effects during development or adulthood cannot be ruled out (Bakos et al., 2009; Kokras and Dalla, 2014). Moreover, although not seen in the present study (possibly due to the low number of animals in each phase of the estrous cycle) the phase of the estrous cycle may influence behavioral responses, as well as hippocampal neurochemistry and neuroplasticity under standard and EE conditions (Kokras and Dalla, 2014). However, since our chronic EE paradigm continued from birth to P90, the estrous cycle would not be a major confounder, as EE would exerted its effects over several developmental stages and gonadal hormone fluctuations.

In summary, this work adds to the current understanding of brain plasticity mechanisms that may be exploited as prophylactic strategies to reduce maladaptive behaviors in adulthood. Its results point to several key neurochemical substrates that underpin the differential response of the two sexes to an exposure to EE combined with physical activity. While both sexes expressed similar behaviors in the present analysis (improved performance in the NOR), these results do not exclude sexually differentiated neurobiological mechanisms. The present findings may be of special relevance to neuropsychiatric and neurodegenerative disorders whose prevalence is sex-biased (e.g. depression and Alzheimer's disease). 


\section{Conflict of interest}

N.K. and CD have received honoraria and financial support from Janssen- Cilag and Elpen S.A. None of those is relevant to this study.

\section{Contributors}

NK contributed to the design of the study and to all experimental procedures with DB \& ELT, performed the statistical analysis and data interpretation. JS assisted in the protein and corticosterone analysis, data interpretation, and compiled the first draft. OFXA and NS contributed to the interpretation of results and provided significant insights. CD supervised and contributed to all parts of this project. All authors contributed to the writing of the manuscript and approved the final manuscript.

\section{Role of funding sources}

NK was supported by ELKE/NKUA:11,650. ELT was supported by TreatAD, 09SYN-21-1003. This work was funded by an "Education and Lifelong Learning, Supporting Postdoctoral Researchers", co-financed by the European Social Fund (ESF) and the General Secretariat for Research and Technology, Greece. This work was also supported by the Portuguese North Regional Operational Program (ON.2) under the National Strategic Reference Framework (QREN), through the European Regional Development Fund (FEDER), the Project Estratégico co-funded by FCT (PEstC/SAU/LA0026/2013) and the European Regional Development Fund COMPETE (FCOMP-01-0124-FEDER-037,298) as well as the project NORTE-01-0145-FEDER-000,013, supported by the Northern Portugal Regional Operational Programme (NORTE 2020), under the Portugal 2020 Partnership Agreement, through the European Regional Development Fund (FEDER). The aforementioned funding agencies had no further role in study design; in the collection, analysis and interpretation of data; in the writing of the report; and in the decision to submit the paper for publication.

\section{Acknowledgments}

None.

\section{References}

Andrade, J.P., Madeira, M., Paula-Barbosa, M., 2000. Sexual dimorphism in the subiculum of the rat hippocampal formation. Brain Res. 875, 125-137.

Antoniou, K., Kafetzopoulos, E., Papadopoulou-Daifoti, Z., Hyphantis, T., Marselos, M., 1998. D-amphetamine, cocaine and caffeine: a comparative study of acute effects on locomotor activity and behavioural patterns in rats. Neurosci. Biobehav. Rev. 23, 189-196.

Arndt, S.S., Laarakker, M.C., van Lith, H.A., van der Staay, F.J., Gieling, E., Salomons, A.R., van't Klooster, J., Ohl, F., 2009. Individual housing of mice-impact on behaviour and stress responses. Physiol. Behav. 97, 385-393.
Bagot, R.C., Tse, Y.C., Nguyen, H.B., Wong, A.S., Meaney, M.J., Wong, T.P., 2012. Maternal care influences hippocampal $\mathrm{N}$-methyl-D-aspartate receptor function and dynamic regulation by corticosterone in adulthood. Biol. Psychiatry 72, 491-498.

Bakos, J., Hlavacova, N., Rajman, M., Ondicova, K., Koros, C., Kitraki, E., Steinbusch, H.W., Jezova, D., 2009. Enriched environment influences hormonal status and hippocampal brain derived neurotrophic factor in a sex dependent manner. Neuroscience 164, 788-797.

Bakota, L., Ussif, A., Jeserich, G., Brandt, R., 2017. Systemic and network functions of the microtubule-associated protein tau: implications for tau-based therapies. Mol. Cell Neurosci 84, 132-141.

Bangasser, D.A., Valentino, R.J., 2014. Sex differences in stress-related psychiatric disorders: neurobiological perspectives. Front. Neuroendocrinol. 35, 303-319.

Baroncelli, L., Sale, A., Viegi, A., Vetencourt, J.F.M., De Pasquale, R., Baldini, S., Maffei, L., 2010. Experience-dependent reactivation of ocular dominance plasticity in the adult visual cortex. Exp. Neurol. 226, 100-109.

Beck, K.D., Luine, V.N., 2002. Sex differences in behavioral and neurochemical profiles after chronic stress: role of housing conditions. Physiol. Behav. 75, 661-673.

Bessinis, D.P., Dalla, C., Daifoti, Z.P., Tiligada, E., 2012. Histamine involvement in visual development and adaptation. Investig. Ophthalmol. Vis. Sci. 53, 7498-7503.

Bessinis, D.P., Dalla, C., Kokras, N., Pitychoutis, P.M., Papadopoulou-Daifoti, Z., 2013. Sex-dependent neurochemical effects of environmental enrichment in the visual system. Neuroscience 254, 130-140.

Bindu, B., Alladi, P., Mansooralikhan, B., Srikumar, B., Raju, T., Kutty, B., 2007. Short-term exposure to an enriched environment enhances dendritic branching but not brain-derived neurotrophic factor expression in the hippocampus of rats with ventral subicular lesions. Neuroscience 144, 412-423.

Blazquez, G., Canete, T., Tobena, A., Gimenez-Llort, L., Fernandez-Teruel, A., 2014. Cognitive and emotional profiles of aged Alzheimer's disease (3xTgAD) mice: effects of environmental enrichment and sexual dimorphism. Behav. Brain Res. 268, 185-201.

Bowman, R.E., Beck, K.D., Luine, V.N., 2003. Chronic stress effects on memory: sex differences in performance and monoaminergic activity. Horm. Behav. 43, 48-59.

Bredy, T.W., Zhang, T.Y., Grant, R.J., Diorio, J., Meaney, M.J., 2004. Peripubertal environmental enrichment reverses the effects of maternal care on hippocampal development and glutamate receptor subunit expression. Eur. J. Neurosci. 20, 1355-1362.

Brenes, J.C., Rodríguez, O., Fornaguera, J., 2008. Differential effect of environment enrichment and social isolation on depressive-like behavior, spontaneous activity and serotonin and norepinephrine concentration in prefrontal cortex and ventral striatum. Pharmacol. Biochem. Behav. 89, 85-93.

Callaghan, B.L., Tottenham, N., 2016. The neuro-environmental loop of plasticity: a cross-species analysis of parental effects on emotion circuitry development following typical and adverse caregiving. Neuropsychopharmacology 41, 163-176.

Cameron, H.A., Schoenfeld, T.J., 2018. Behavioral and structural adaptations to stress. Front. Neuroendocrinol 49, 106-113.

Carvalho-Netto, E.F., Myers, B., Jones, K., Solomon, M.B., Herman, J.P., 2011. Sex differences in synaptic plasticity in stress-responsive brain regions following chronic variable stress. Physiol. Behav. 104, 242-247.

Chen, Q., Zhou, Z., Zhang, L., Wang, Y., Zhang, Y.W., Zhong, M., Xu, S.C., Chen, C.H., Li, L., Yu, Z.P., 2012. Tau protein is involved in morphological plasticity in hippocampal neurons in response to BDNF. Neurochem. Int. 60, 233-242.

Clark, R.E., Zola, S.M., Squire, L.R., 2000. Impaired recognition memory in rats after damage to the hippocampus. J. Neurosci. 20, 8853-8860. 
Coley, A.A., Gao, W.J., 2018. PSD95: a synaptic protein implicated in schizophrenia or autism? Prog. Neuropsychopharmacol. Biol. Psychiatry 82, 187-194.

Connors, E.J., Migliore, M.M., Pillsbury, S.L., Shaik, A.N., Kentner, A.C., 2015. Environmental enrichment models a naturalistic form of maternal separation and shapes the anxiety response patterns of offspring. Psychoneuroendocrinology 52, 153-167.

Dalla, C., Antoniou, K., Drossopoulou, G., Xagoraris, M., Kokras, N., Sfikakis, A., Papadopoulou-Daifoti, Z., 2005. Chronic mild stress impact: are females more vulnerable? Neuroscience 135, 703-714.

Dalla, C., Antoniou, K., Kokras, N., Drossopoulou, G., Papathanasiou, G., Bekris, S., Daskas, S., Papadopoulou-Daifoti, Z., 2008. Sex differences in the effects of two stress paradigms on dopaminergic neurotransmission. Physiol. Behav. 93, 595-605.

Dalla, C., Pitychoutis, P.M., Kokras, N., Papadopoulou-Daifoti, Z., 2010. Sex differences in animal models of depression and antidepressant response. Basic Clin. Pharmacol. Toxicol. 106, 226-233.

Dalla, C., Shors, T.J., 2009. Sex differences in learning processes of classical and operant conditioning. Physiol. Behav. 97, 229-238.

Dalla, C., Whetstone, A.S., Hodes, G.E., Shors, T.J., 2009. Stressful experience has opposite effects on dendritic spines in the hippocampus of cycling versus masculinized females. Neurosci. Lett. 449, 52-56.

Del Arco, A., Segovia, G., Garrido, P., de Blas, M., Mora, F., 2007. Stress, prefrontal cortex and environmental enrichment: studies on dopamine and acetylcholine release and working memory performance in rats. Behav. Brain Res. 176, 267-273.

Fischer, A., 2016. Environmental enrichment as a method to improve cognitive function. What can we learn from animal models? Neuroimage 131, 42-47.

Fleming, A.S., O'Day, D.H., Kraemer, G.W., 1999. Neurobiology of mother-infant interactions: experience and central nervous system plasticity across development and generations. Neurosci. Biobehav. Rev. 23, 673-685.

Frandemiche, M.L., De Seranno, S., Rush, T., Borel, E., Elie, A., Arnal, I., Lanté, F., Buisson, A., 2014. Activity-dependent tau protein translocation to excitatory synapse is disrupted by exposure to amyloid-beta oligomers. J. Neurosci. 34, 6084-6097.

Frick, K.M., Gresack, J.E., 2003. Sex differences in the behavioral response to spatial and object novelty in adult C57BL/6 mice. Behav. Neurosci. 117, 1283.

Gemmel, M., Kokras, N., Dalla, C., Pawluski, J.L., 2017. Perinatal fluoxetine prevents the effect of pre-gestational maternal stress on 5-HT in the PFC, but maternal stress has enduring effects on mPFC synaptic structure in offspring. Neuropharmacology 128 , 168-180.

Gemmel, M., Rayen, I., van Donkelaar, E., Loftus, T., Steinbusch, H.W., Kokras, N., Dalla, C., Pawluski, J.L., 2016. Gestational stress and fluoxetine treatment differentially affect plasticity, methylation and serotonin levels in the PFC and hippocampus of rat dams. Neuroscience $327,32-43$.

Girbovan, C., Plamondon, H., 2013a. Environmental enrichment in female rodents: considerations in the effects on behavior and biochemical markers. Behav. Brain Res. 253, 178-190.

Girbovan, C., Plamondon, H., 2013b. Environmental enrichment in female rodents: considerations in the effects on behavior and biochemical markers. Behav. Brain Res. 253, 178-190.

Greengard, P., Valtorta, F., Czernik, A.J., Benfenati, F., 1993. Synaptic vesicle phosphoproteins and regulation of synaptic function. Science 259, 780.

Gualtieri, F., Bregere, C., Laws, G.C., Armstrong, E.A., Wylie, N.J., Moxham, T.T., Guzman, R., Boswell, T., Smulders, T.V., 2017. Effects of environmental enrichment on doublecortin and bdnf expression along the dorso-ventral axis of the dentate gyrus. Front. Neurosci. 11, 488.
Harati, H., Barbelivien, A., Herbeaux, K., Muller, M.-A., Engeln, M., Kelche, C., Cassel, J.-C., Majchrzak, M., 2013. Lifelong environmental enrichment in rats: impact on emotional behavior, spatial memory vividness, and cholinergic neurons over the lifespan. Age 35, 1027-1043.

Hattori, S., Hashimoto, R., Miyakawa, T., Yamanaka, H., Maeno, H., Wada, K., Kunugi, H., 2007. Enriched environments influence depression-related behavior in adult mice and the survival of newborn cells in their hippocampi. Behav. Brain Res. 180, 69-76.

Hendershott, T.R., Cronin, M.E., Langella, S., McGuinness, P.S., Basu, A.C., 2016. Effects of environmental enrichment on anxiety-like behavior, sociability, sensory gating, and spatial learning in male and female C57BL/6 J mice. Behav. Brain Res. 314, 215-225.

Ittner, L.M., Ke, Y.D., Delerue, F., Bi, M., Gladbach, A., van Eersel, J., Wölfing, H., Chieng, B.C., Christie, M.J., Napier, I.A., 2010. Dendritic function of tau mediates amyloid- $\beta$ toxicity in Alzheimer's disease mouse models. Cell 142, 387-397.

Kafetzopoulos, V., Kokras, N., Sotiropoulos, I., Oliveira, J.F., Leite-Almeida, H., Vasalou, A., Sardinha, V.M., PapadopoulouDaifoti, Z., Almeida, O.F., Antoniou, K., Sousa, N., Dalla, C., 2018. The nucleus reuniens: a key node in the neurocircuitry of stress and depression. Mol. Psychiatry 23, 579-586.

Kempadoo, K.A., Mosharov, E.V., Choi, S.J., Sulzer, D., Kandel, E.R., 2016. Dopamine release from the locus coeruleus to the dorsal hippocampus promotes spatial learning and memory. Proc. Natl. Acad. Sci. U. S.A. 113, 14835-14840.

Kentner, A.C., 2015. Neuroprotection and recovery from early-life adversity: considerations for environmental enrichment. Neural Regen. Res. 10, 1545-1547.

Kentner, A.C., Lima, E., Migliore, M.M., Shin, J., Scalia, S., 2018. Complex environmental rearing enhances social salience and affects hippocampal corticotropin releasing hormone receptor expression in a sex-specific manner. Neuroscience 369, 399-411.

Kimura, T., Whitcomb, D.J., Jo, J., Regan, P., Piers, T., Heo, S., Brown, C., Hashikawa, T., Murayama, M., Seok, H., 2014. Microtubule-associated protein tau is essential for long-term depression in the hippocampus. Philos. Trans. R. Soc. B 369, 20130144.

Kobayashi, S., Tanaka, T., Soeda, Y., Almeida, O.F., Takashima, A., 2017. Local somatodendritic translation and hyperphosphorylation of tau protein triggered by AMPA and NMDA receptor stimulation. EBioMedicine 20, 120-126.

Kokras, N., Antoniou, K., Mikail, H.G., Kafetzopoulos, V., Papadopoulou-Daifoti, Z., Dalla, C., 2015. Forced swim test: what about females? Neuropharmacology 99, 408-421.

Kokras, N., Antoniou, K., Polissidis, A., Papadopoulou-Daifoti, Z., 2009. Antidepressants induce regionally discrete, sex-dependent changes in brain's glutamate content. Neurosci. Lett. 464, 98-102.

Kokras, N., Baltas, D., Theocharis, F., Dalla, C., 2017. Kinoscope: an open-source computer program for behavioral pharmacologists. Front. Behav. Neurosci. 11, 88.

Kokras, N., Dalla, C., 2014. Sex differences in animal models of psychiatric disorders. Br. J. Pharmacol. 171, 4595-4619.

Kokras, N., Dalla, C., 2017. Preclinical sex differences in depression and antidepressant response: implications for clinical research. J. Neurosci. Res. 95, 731-736.

Kokras, N., Dalla, C., Sideris, A.C., Dendi, A., Mikail, H.G., Antoniou, K., Papadopoulou-Daifoti, Z., 2012. Behavioral sexual dimorphism in models of anxiety and depression due to changes in HPA axis activity. Neuropharmacology 62, 436-445.

Kokras, N., Pastromas, N., Papasava, D., de Bournonville, C., Cornil, C.A., Dalla, C., 2018. Sex differences in behavioral and neurochemical effects of gonadectomy and aromatase inhibition in rats. Psychoneuroendocrinology 87, 93-107. 
Kokras, N., Sotiropoulos, I., Pitychoutis, P.M., Almeida, O.F., Papadopoulou-Daifoti, Z., 2011. Citalopram-mediated anxiolysis and differing neurobiological responses in both sexes of a genetic model of depression. Neuroscience 194, 62-71.

Kornau, H.-C., Schenker, L.T., Kennedy, M.B., Seeburg, P.H., 1995. Domain interaction between NMDA receptor subunits and the postsynaptic density protein PSD-95. Science 269, 1737.

Kyratsas, C., Dalla, C., Anderzhanova, E., Polissidis, A., Kokras, N., Konstantinides, K., Papadopoulou-Daifoti, Z., 2013. Experimental evidence for sildenafil's action in the central nervous system: dopamine and serotonin changes in the medial preoptic area and nucleus accumbens during sexual arousal. J. Sex Med. 10, 719-729.

Läck, A., Gill, K., Porrino, L., 2010. Local cerebral glucose utilization in rats exposed to an enriched environment: a comparison to impoverishment. Pharmacol. Biochem. Behav. 96, 521-525.

Lambert, T.J., Fernandez, S.M., Frick, K.M., 2005. Different types of environmental enrichment have discrepant effects on spatial memory and synaptophysin levels in female mice. Neurobiol. Learn. Mem. 83, 206-216.

Lee, G., Newman, S.T., Gard, D.L., Band, H., Panchamoorthy, G., 1998. Tau interacts with src-family non-receptor tyrosine kinases. J. Cell Sci. 111, 3167-3177.

Li, K.A., Lund, E.T., Voigt, J.P., 2016. The impact of early postnatal environmental enrichment on maternal care and offspring behaviour following weaning. Behav. Process. 122, 51-58.

Liu, D., Diorio, J., Day, J.C., Francis, D.D., Meaney, M.J., 2000. Maternal care, hippocampal synaptogenesis and cognitive development in rats. Nat. Neurosci. 3, 799-806.

Lopes, S., Vaz-Silva, J., Pinto, V., Dalla, C., Kokras, N., Bedenk, B., Mack, N., Czisch, M., Almeida, O.F., Sousa, N., Sotiropoulos, I., 2016. Tau protein is essential for stress-induced brain pathology. Proc. Natl. Acad. Sci. U. S. A. 113, E3755-E3763.

Luine, V., 2002. Sex differences in chronic stress effects on memory in rats. Stress 5, 205-216.

McQuaid, R.J., Audet, M.-C., Jacobson-Pick, S., Anisman, H., 2012. The differential impact of social defeat on mice living in isolation or groups in an enriched environment: plasma corticosterone and monoamine variations. Int. J. Neuropsychopharmacol. 16, 351-363.

Melo, A., Kokras, N., Dalla, C., Ferreira, C., Ventura-Silva, A.P., Sousa, N., Pego, J.M., 2015. The positive effect on ketamine as a priming adjuvant in antidepressant treatment. Transl. Psychiatry 5 , e573.

Mikail, H.G., Dalla, C., Kokras, N., Kafetzopoulos, V., Papadopoulou-Daifoti, Z., 2012. Sertraline behavioral response associates closer and dose-dependently with cortical rather than hippocampal serotonergic activity in the rat forced swim stress. Physiol. Behav. 107, 201-206.

Mileva, G.R., Bielajew, C., 2015. Environmental manipulation affects depressive-like behaviours in female Wistar-Kyoto rats. Behav. Brain Res. 293, 208-216.

Moore, S.J., Deshpande, K., Stinnett, G.S., Seasholtz, A.F., Murphy, G.G., 2013. Conversion of short-term to long-term memory in the novel object recognition paradigm. Neurobiol. Learn. Mem. 105, 174-185.

Moreno-Castilla, P., Perez-Ortega, R., Violante-Soria, V., Balderas, I., Bermudez-Rattoni, F., 2017. Hippocampal release of dopamine and norepinephrine encodes novel contextual information. Hippocampus 27, 547-557.

Morgado, P., Marques, F., Ribeiro, B., Leite-Almeida, H., Pego, J.M., Rodrigues, A.J., Dalla, C., Kokras, N., Sousa, N., Cerqueira, J.J., 2015. Stress induced risk-aversion is reverted by D2/D3 agonist in the rat. Eur. Neuropsychopharmacol. 25, 1744-1752.

Murgatroyd, C., Patchev, A.V., Wu, Y., Micale, V., Bockmühl, Y., Fischer, D., Holsboer, F., Wotjak, C.T., Almeida, O.F., Spengler, D., 2009. Dynamic DNA methylation programs persistent adverse effects of early-life stress. Nat. Neurosci. 12, 1559-1566.
Nithianantharajah, J., Hannan, A.J., 2006. Enriched environments, experience-dependent plasticity and disorders of the nervous system. Nat. Rev. Neurosci. 7, 697-709.

Novais, A., Ferreira, A.C., Marques, F., Pego, J.M., Cerqueira, J.J., David-Pereira, A., Campos, F.L., Dalla, C., Kokras, N., Sousa, N., Palha, J.A., Sousa, J.C., 2013. Neudesin is involved in anxiety behavior: structural and neurochemical correlates. Front. Behav. Neurosci. 7, 119.

Pang, T.Y., Hannan, A.J., 2013. Enhancement of cognitive function in models of brain disease through environmental enrichment and physical activity. Neuropharmacology 64, 515-528.

Pena, Y., Prunell, M., Rotllant, D., Armario, A., Escorihuela, R.M., 2009. Enduring effects of environmental enrichment from weaning to adulthood on pituitary-adrenal function, pre-pulse inhibition and learning in male and female rats. Psychoneuroendocrinology 34, 1390-1404.

Pitychoutis, P.M., Dalla, C., Sideris, A.C., Tsonis, P.A., Papadopoulou-Daifoti, Z., 2012. 5-HT(1A), 5-HT(2A), and 5-HT(2C) receptor mRNA modulation by antidepressant treatment in the chronic mild stress model of depression: sex differences exposed. Neuroscience 210, 152-167.

Pooler, A.M., Usardi, A., Evans, C.J., Philpott, K.L., Noble, W., Hanger, D.P., 2012. Dynamic association of tau with neuronal membranes is regulated by phosphorylation. Neurobiol. Aging 33 (431), e427-e438.

Rehm, H., Wiedenmann, B., Betz, H., 1986. Molecular characterization of synaptophysin, a major calcium-binding protein of the synaptic vesicle membrane. EMBO J. 5, 535.

Rogers, J., Vo, U., Buret, L.S., Pang, T.Y., Meiklejohn, H., Zeleznikow-Johnston, A., Churilov, L., van den Buuse, M., Hannan, A.J., Renoir, T., 2016. Dissociating the therapeutic effects of environmental enrichment and exercise in a mouse model of anxiety with cognitive impairment. Transl. Psychiatry 6, e794.

Ronca, A.E., Lamkin, C.A., Alberts, J.R., 1993. Maternal contributions to sensory experience in the fetal and newborn rat (Rattus norvegicus). J. Comp. Psychol. 107, 61.

Shors, T.J., 2004. Memory traces of trace memories: neurogenesis, synaptogenesis and awareness. Trends Neurosci. 27, 250-256.

Shors, T.J., Chua, C., Falduto, J., 2001. Sex differences and opposite effects of stress on dendritic spine density in the male versus female hippocampus. J. Neurosci. 21, 6292-6297.

Sifonios, L., Trinchero, M., Cereseto, M., Ferrero, A., Cladouchos, M., Macedo, G.F., Reinés, A., Wikinski, S., 2009. An enriched environment restores normal behavior while providing cytoskeletal restoration and synaptic changes in the hippocampus of rats exposed to an experimental model of depression. Neuroscience 164, 929-940.

Simpson, J., Kelly, J.P., 2011a. The impact of environmental enrichment in laboratory rats-behavioural and neurochemical aspects. Behav. Brain Res. 222, 246-264.

Simpson, J., Kelly, J.P., 2011b. The impact of environmental enrichment in laboratory rats-behavioural and neurochemical aspects. Behav. Brain Res. 222, 246-264.

Sotiropoulos, I., Catania, C., Pinto, L.G., Silva, R., Pollerberg, G.E., Takashima, A., Sousa, N., Almeida, O.F., 2011. Stress acts cumulatively to precipitate Alzheimer's disease-like tau pathology and cognitive deficits. J. Neurosci. 31, 7840-7847.

Sotiropoulos, I., Silva, J., Kimura, T., Rodrigues, A.J., Costa, P., Almeida, O.F., Sousa, N., Takashima, A., 2015. Female hippocampus vulnerability to environmental stress, a precipitating factor in Tau aggregation pathology. J. Alzheimers Dis. 43, 763-774.

Sousa, N., 2016. The dynamics of the stress neuromatrix. Mol. Psychiatry $21,302-312$.

Sousa, N., Almeida, O.F., 2002. Corticosteroids: sculptors of the hippocampal formation. Rev. Neurosci. 13, 59-84. 
Sutcliffe, J., Marshall, K., Neill, J., 2007a. Influence of gender on working and spatial memory in the novel object recognition task in the rat. Behav. Brain Res. 177, 117-125.

Sutcliffe, J.S., Marshall, K.M., Neill, J.C., 2007b. Influence of gender on working and spatial memory in the novel object recognition task in the rat. Behav. Brain Res. 177, 117-125.

Tanti, A., Rainer, Q., Minier, F., Surget, A., Belzung, C., 2012. Differential environmental regulation of neurogenesis along the septo-temporal axis of the hippocampus. Neuropharmacology 63 , 374-384.

Trepanier, C.H., Jackson, M.F., MacDonald, J.F., 2012. Regulation of NMDA receptors by the tyrosine kinase Fyn. FEBS J. 279, 12-19.

Van de Weerd, H., Van Loo, P., Van Zutphen, L., Koolhaas, J., Baumans, V., 1997. Nesting material as environmental enrichment has no adverse effects on behavior and physiology of laboratory mice. Physiol. Behav. 62, 1019-1028.

Vyas, S., Rodrigues, A.J., Silva, J.M., Tronche, F., Almeida, O.F., Sousa, N., Sotiropoulos, I., 2016. Chronic stress and glucocorticoids: from neuronal plasticity to neurodegeneration. Neural Plast. 2016, 6391686.

Welberg, L., Thrivikraman, K., Plotsky, P., 2006. Combined pre-and postnatal environmental enrichment programs the HPA axis differentially in male and female rats. Psychoneuroendocrinology $31,553-564$
Wittchen, H.-U., Jacobi, F., Rehm, J., Gustavsson, A., Svensson, M., Jönsson, B., Olesen, J., Allgulander, C., Alonso, J., Faravelli, C., 2011. The size and burden of mental disorders and other disorders of the brain in Europe 2010. Eur. Neuropsychopharmacol. 21, 655-679.

Wu, Y., Patchev, A.V., Daniel, G., Almeida, O.F., Spengler, D., 2014. Early-life stress reduces DNA methylation of the Pomc gene in male mice. Endocrinology 155, 1751-1762.

Zhang, T.Y., Keown, C.L., Wen, X., Li, J., Vousden, D.A. Anacker, C., Bhattacharyya, U., Ryan, R., Diorio, J., O'Toole, N., Lerch, J.P., Mukamel, E.A., Meaney, M.J., 2018. Environmental enrichment increases transcriptional and epigenetic differentiation between mouse dorsal and ventral dentate gyrus. Nat. Commun. 9, 298

Zheng, J., Jiang, Y.Y., Xu, L.C., Ma, L.Y., Liu, F.Y., Cui, S., Cai, J., Liao, F.F., Wan, Y., Yi, M., 2017. Adult hippocampal neurogenesis along the dorsoventral axis contributes differentially to environmental enrichment combined with voluntary exercise in alleviating chronic inflammatory pain in mice. J. Neurosci. 37, 4145-4157. 